\title{
Access to adequate water in post-apartheid South African provinces: An overview of numerical trends
}

\author{
RC Nnadozie* \\ Department of Civil Engineering, Mangosuthu University of Technology, PO Box 12363, Jacobs 4026, South Africa
}

\begin{abstract}
This paper presents an insight into water service access and demand, with a numerical review of official data from the national household survey from 1995 to 2006, and the 1996 and 2001 census data. The findings show that in provinces (Eastern Cape, Limpopo and Mpumalanga) where the existing service base is low, with a relatively high level of outmigration leading to a decrease in household numbers, the annual rate of delivery is lower than in other areas and percentage access has risen marginally (from about $68 \%$ to $70 \%$ ). In provinces (North West, Northern Cape and KwaZulu-Natal) where the existing service base is higher, with relatively lower levels of out-migration, there is a marginal change in household numbers and the annual rate of delivery is higher and percentage access has risen remarkably (from about $72 \%$ to $88 \%$ ). In the provinces (Gauteng, Western Cape and Free State) with the most favourable initial conditions, that is, where the existing service base is the highest, there is a remarkable change in household numbers, possibly as a result of in-migration and the annual rate of delivery is quite sustainable. Percentage access rises at an early stage and remains stable at the limiting value of about $98 \%$.
\end{abstract}

Keywords: water access, water demand, piped water, backlog, households, population, in-migration, out-migration

\section{Introduction}

Access to water is basic to life and is recognised as a fundamental human right. A healthy human life demands sufficient and safe water. In South African law and policy, basic water supply must be sufficient, safe, accessible and affordable. Basic water must also be provided continuously with a stipulated minimum rate of flow and quality (Hemson and Galvin, 2006).

During the apartheid era, there was no central department of Government that was dedicated to universal supply and management of water resources in South Africa. Homeland governments ran water service infrastructures (DWAF, 2004). In poorer black rural areas these were run inefficiently by uncoordinated homeland government structures that were almost completely dependent on the South African Government for funding. Consequently, in 1994 it was estimated that 30\% of the South African population lacked access to adequate water supply services and that $50 \%$ were without adequate sanitation (DWAF, 2004).

The post-apartheid government instituted the Reconstruction and Development Programme (RDP) as the policy foundation stone of the new government. The RDP gave the Department of Water Affairs and Forestry (DWAF) the responsibility of ensuring universal access to basic water services for all South Africans. Subsequently, the White Paper on Water and Sanitation was released in 1994, with emphasis on speedy delivery of water and sanitation services to ensure that all South Africans have access to a basic water supply (DWAF, 2004). Exactly 10 years (2004) into democracy the then President of South Africa, Mbeki, in one of the most remarkable State of the Nation addresses, made various time-bound

\footnotetext{
* To whom all correspondence should be addressed.

용 +2731907 7192; fax: +2731907 7208;

e-mail: Nnadozie@mut.ac.za

Received 2 October 2010; accepted in revised form 30 May 2011.
}

promises on the key issues around household services, education, health care and security. Regarding access to water, President Mbeki promised that 'within the next 5 years all households will have access to clean running water' (Mbeki, 2004). The RDP and subsequent development programmes, the presidential targets and, at the international level, Target 10 of the Millennium Development Goals (halve by 2015 the proportion of people without sustainable access to safe drinking water and basic sanitation), are all time-bound development commitments that require consistent measurement of progress towards achieving the targets.

The work of Hirschowitz and Okin (1997) was one of the earlier attempts in using official statistics to measure development and living conditions in South African households, on a relative basis, in the post-apartheid era. Using the October 1994 household survey the study found wide disparities in the odds of access to basic services for different demographic segments of South African society. Black African households were found to be more likely to lack access to basic services: housing, water, sanitation and electricity, amongst others (Hirschowitz and Okin, 1997). A similar study that was done in 1999 compared access to basic services on the basis of household income; this study found that access to basic services was closely related to income. Households that belonged to the low-income group were more likely to be excluded from access to basic services (Budlender, 1999). Therefore, one of the primary focuses of various regimes of the new era has been service delivery and infrastructural development for previously disadvantaged communities.

More recent studies on the issue of measurement of service delivery and living conditions in South African households confirm that the focus is to deliver to poor households. For instance Bhorat and co-workers (Bhorat et al., 2004; Bhorat and Canbur, 2005; Bhorat et al., 2008a;b), in their studies on the shift in non-income welfare in South Africa, reveal that the focus of the government welfare services in the post-apartheid 
era has been pro-poor. Households at the bottom of the expenditure deciles (poorest of the poor) were found to have benefited more from government services. However, even though delivery seems to have been pro-poor, significant backlogs were noted in these studies among poor households, especially with respect to housing, sanitation and piped water. These results are further confirmed by the work of Hemson and O'Donovan (2006), in which it is also observed that substantial progress has been made, but that a lot more effort is needed for universal access to basic services in South Africa. These studies also observed that a major impediment towards reaching service delivery targets for water and other household-based services is the issue of the rapid increase in the number of households in recent years in South Africa, a phenomenon which operates somewhat independently of increases in population. This has complicated and dramatically added to the numbers demanding access to basic services. The 1996 census recorded about 9 million households; this number increased by almost $38 \%$ to about 12.5 million households in 2007, as revealed by the 2007 community survey, while the individual population increased by about $20 \%$ from 40.5 million to 48.5 million over the same period.

This research has responded to debates about water service delivery at the national and provincial levels by undertaking a comprehensive numerical review of trends of access to and demand for adequate water supply in South African provinces. The emphasis is on the review of numerical trends in absolute number, for purposes of practical planning and logistics. Numerical trends in absolute number values are vital, even though historical data may sometimes yield inconsistent values during analysis. As stated earlier, without good information on the trends in terms of numbers it becomes quite cumbersome to measure progress on targets, prepare dynamic budgets and make forecasts for the future. This gap is partly what this study intends to fill, by providing a numerically-based approach with most results in absolute numbers, geared towards the purpose of practical planning.

This paper concentrates on the question of whether the reported substantial unevenness in delivery according to provinces exists, and further whether there is a narrowing of any identified divide between provinces in favour of the poorest. The research thus examines whether there are leads and lags among provinces and whether these variances are narrowing or increasing. The expectation of comprehensive delivery to all is that those provinces identified as having the largest backlogs will advance in delivery at the most rapid pace and that the differences between provinces should narrow steadily. The household data from the 1995 October Household Survey (OHS), 1999 OHS and the 2005 General Household Survey (GHS) were analysed to identify backlogs and trends and to draw conclusions, by province, about progress towards social goals.

The objectives of this study were to carry out a numerical analysis to answer the following questions:

- Are there substantial differences between provinces in terms of access to and demand for piped water and, if so, to what can these difference be attributed?

- Is unevenness in delivery being remedied in light of governmental and institutional targets of universal access to adequate water?

It is obvious that the delivery of adequate water supply succeeds or fails at local government level; therefore, it is interesting to measure and observe variations at this level of government. However, this analysis is geared towards contributing to the pool of information for national and various provincial governments and other stakeholders; such information could be valuable for these tiers of government in various ways, for instance, the assessment of progress and the preparation of the provincial growth and development strategies of various provincial governments with respect to supply of adequate water.

Ideally, the analysis of supply of adequate water is done along with that of sanitation. Sanitation was not included in this review because this is intended to focus on water; secondly, there is controversy as to the definition of what constitutes adequate sanitation. In some areas the ventilated improved pit (VIP) toilets are accepted as minimum standard while the urine diversion (UD) toilet is the accepted minimum standard in other areas. Some communities regard the flush toilet system as their operational standard. With these ambiguities analysis of sanitation is left to be treated as a separate study. It is worth mentioning though that sanitation delivery has lagged behind adequate water supply by a significant margin over the period examined, irrespective of the standard of measurement The 2007 community survey shows that about $21 \%$ of South African households are still using the pit toilet system without ventilation, while $8 \%$ have no toilet facilities at all (Statistics South Africa, 2007).

\section{Data sources and methodology}

This study is secondary research in that a desktop approach was used. The bulk of data used for this study are from the South African national censuses of 1996 and 2001, and national household surveys conducted by Statistics South Africa. The surveys include the October Household Surveys from 1994 to 1999, the General Household Surveys from 2002 to 2005 and the Community Surveys of 2007. Ten per cent samples of these data sets have been accessed through the national data archive. The census and survey basically collected socioeconomic person and household data on the following themes; demographics, household services and welfare, income and expenditure, land access and use and general perceptions of household dwellers, amongst others. These data sets are explored and analysed using the Statistical Package for Social Sciences (SPSS).

The survey questionnaire from Statistics South Africa, on the question of the source of water for households included the following options: piped water to dwelling, piped water to yard, neighbours' tap, piped water to community stand, borehole, spring, river, dam, stagnant water/pool, water tanker, and rain water. Although there are slight variations in the definition of access levels from the earlier October Household Surveys to the recent General Household Surveys, the variations do not make any significant difference. For simplicity we proceeded by summarising the levels of household access based on 2 broad categories of water sources, that is, households that met the minimum basic regulatory standard of water access (households with access to piped water not more than $200 \mathrm{~m}$ away from their dwelling) and those that do not. Households under the first category 'Piped Households' or 'Basic Access' are those with running tap-water in the dwelling, running tap-water on site and households with access to public taps. All other sources of water are considered not to be to regulatory standards and therefore are referred to as 'Backlog' or 'No Access'. The computations are based on the primary assumption that new or fragmenting households require state assistance for access to piped water. 
The computations are presented in tables with consideration of the following elements: the existing number of households without services, changes in the number of households leading to additional demand and a calculation of the rate at which additional access is being provided. Yearly additional access is the difference between total access in the current year and total access of the previous year. Backlog is computed with the expression below, where the first 2 elements provide a figure for the historical element carried over from previous years, to which the current additional demand is added, from which the additional number having access can be subtracted. The current backlog is the result of the following: Carryover Backlog + Additional number of households - Additional number of households gaining access. The notational description is as follows; $B_{t}=\left(B_{t-1}+A D\right)-A C$, where $B_{t}$ is the backlog for the current year/time, $B_{t-1}$ is the carryover of historic backlog from the previous year, i.e. (current year - one year). The backlog computation does not account for other constitutional dimensions of basic water, such as water quality and rate of flow. $A D$ is the additional demand for the current year resulting from increase in households and $A C$ is the additional access/connection for the current year.

The main issue pertaining to the difficulty of working with historical survey data in South Africa could be that of the fluctuating population base from which the national surveys are sampled and benchmarked. For instance, the Household Surveys done after the 1996 census used 1996 population census as a base while the earlier surveys used the 1991 census as the base. The 1991 census did not include Transkei, Venda, Bophuthatswana and Ciskei (the so-called TBVC states) and hence the size of these populations had to be estimated and added later. Consequently, survey data are always reweighted as new information emerges; this is one of the possible causes of fluctuations and inconsistency in trends of various variables. We used a grouping strategy which matched the provinces into 3 groups according to levels of access to water; auspiciously the majority of the provinces from the former TBVC states (the main source of the fluctuations) belong to 1 group, and this reduced the fluctuation, especially within the other 2 groups. Comparison is then made in 2 periods or phases, i.e. the periods 1995-1999 (Phase I) and 1999-2005 (Phase II), to identify any changes in the pace of delivery. The dynamics of access within the groups are identified and differences related to the proportion of households connected and to previous trends in delivery are analysed. Finally, the trends in access for the different provincial groups are mathematically modelled using the logistic, exponential and linear models, respectively.

\section{Findings and discussion}

The dynamics of access at national level and within the provinces are identified and differences related to the numbers and proportions of households connected are analysed. The data is examined to identify the extent of 'catch up' development whereby lesser developed provinces advance in the pace of delivery.

\section{National scenario}

Household water access at the national level was computed based on the 2 categories, i.e. Piped and Backlog, as defined in the methodology section. The results that are presented in Table 1 are derived from the SPSS output from the analysis of data from national household surveys.

\begin{tabular}{|l|l|l|l|l|l|}
\hline \multicolumn{7}{|c|}{ Table 1 } \\
\hline Year & HH & Total piped & Backlog & $\begin{array}{l}\text { +Connec- } \\
\text { tion }\end{array}$ & $\begin{array}{l}\% \\
\text { Piped }\end{array}$ \\
\hline 1994 & 8651815 & 6555466 & 2096350 & 455770 & 75.8 \\
\hline 1995 & 8802344 & 7011235 & 1791109 & 412562 & 79.7 \\
\hline 1996 & 9053596 & 7423797 & 1629799 & 188931 & 82.0 \\
\hline 1997 & 9301283 & 7612728 & 1688555 & 7470 & 81.8 \\
\hline 1998 & 9283513 & 7620198 & 1663315 & 1402012 & 82.1 \\
\hline 1999 & 10798643 & 9022209 & 1776434 & 121671 & 83.5 \\
\hline 2000 & 10944768 & 9143880 & 1800888 & 723371 & 83.5 \\
\hline 2002 & 11780379 & 9867251 & 1913128 & 933890 & 83.8 \\
\hline 2003 & 12538588 & 10801141 & 1737447 & 32832 & 86.1 \\
\hline 2004 & 12624143 & 10833973 & 1790170 & 254756 & 85.8 \\
\hline 2005 & 12726270 & 11088729 & 1637542 & 250000 & 87.1 \\
\hline
\end{tabular}

Source: Computed from Stats SA Household Surveys 94 - 05

In Table 1 we see that total households increased from 8.7 million in 1994 to about 12.7 million in 2005, i.e. about a $46 \%$ increase. Households with access to piped water increased from 6.6 million in 1994 to 11 million in 2005, an increase of above $69 \%$ in percentage terms. This implies that, all things being equal, about 4 million additional connections were delivered over that period, but these additional connections must be considered against the 4.5 million additional demand or addition to backlog as a result of rapidly-growing household numbers, neglecting particular households that were formed and dissolved within the period as these cancel out. Column 5 (+Connection) in Table 1 shows an indicator of yearly delivery or additional connection on a yearly basis, i.e., the difference between total households with piped water in the current year and total households with piped water in the following year. The yearly delivery data are very erratic and this clearly illustrates the difficulty of undertaking a year by year monitoring and evaluation of delivery of basic services in numerical terms. The last column in Table 1 shows the percentage of households with access to piped water. This increased from $75.8 \%$ in 1994 to $87.1 \%$ in 2005 , which is a reasonable achievement over the period. On the other hand, the backlog was still lingering at 1.6 million households.

The figures presented in Table 1 and the rest of the analysis for backlog, should be interpreted with caution because all of the constitutional dimensions of adequate water access, such as water quality, and rate of flow of taps, are not factored into the computations for backlog. This implies that the actual backlog values, when these technical dimensions are considered, could be greater than reported here. For instance the water services information system reported a backlog of about 3.9 million for 1994, when all of the dimensions of water quality are considered, in comparison to the value used in this study, of about 2.1 million for the same period (DWA, 2011). Here the focus is on connection of households and communities to the national and provincial grid bringing piped water to the dwelling, yard or at distances less than the stipulated $200 \mathrm{~m}$.

Even though the data is erratic, the trend line (95\% confidence interval for $x$ : $-.0541329,0456231)$ in Fig. 1 shows that the new connection (i.e. delivery) to backlog ratio has remained almost static throughout the period 1994 to 2005. This is why the backlog was still at about 1.6 million in 2005 despite the 4 million connections over the period. With an average household size of about 3.7 in the series as shown by the data, the 1.6 million household backlogs would translate to about 6 million persons. Therefore the mass action/service delivery 


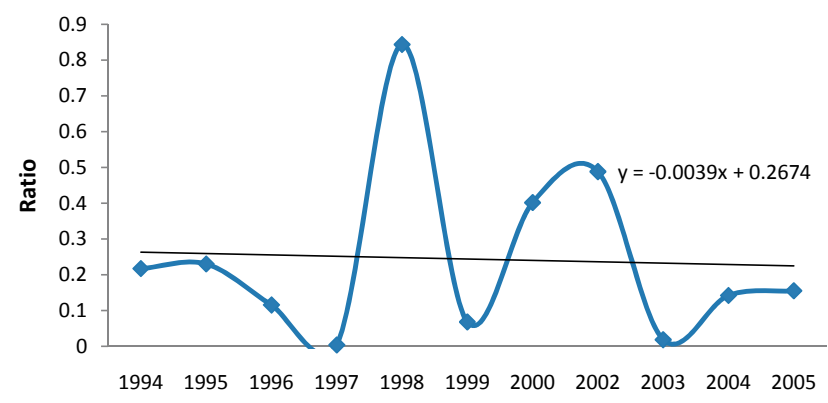

Year

Figure 1

Matching new connection with backlog

protests should not be surprising, even though some of the indices are showing remarkable progress in delivery.

For simplicity we denote the time periods 1995 to 1999 and 1999 to 2005 as Phase I and Phase II, respectively. We break the analysis down into these 2 periods; this breakdown was mainly for computational convenience and to make it easier to conceptualise progress for periods close to 1994 and onwards.

Table 2
\begin{tabular}{|l|c|c|}
\hline \multicolumn{3}{|c|}{ Changes in households, backlog and delivery } \\
\hline Parameter & Phase I & Phase II \\
\hline Average annual change in backlog & -9 & 22111 \\
\hline Average annual additional demand & 502743 & 355975 \\
\hline Average annual delivery & 502734 & 382508 \\
\hline
\end{tabular}
Source: Computed from Stats SA Household Surveys 94 - 05

A deeper enquiry into the volume of delivery on a progressive annual basis, within the phases, reveals in Table 2 that the average annual additional access (delivery) declined from 502743 to about 355975 from Phase I to Phase II. Annual additional demand also declined to almost the same measure between the phases. Therefore, the increasing percentage access does not really imply accelerated delivery in all of the provinces, but could be as a result of changing household dynamics impacting upon additional demand over these phases.

The critical issue is to investigate whether targets like the presidential time-bound promises and the Millennium Development Targets could be reached, first at national level and then in the provinces, if the existing level of delivery is boosted and sustained. We also assess whether there is evidence of disparity and unevenness in terms of backlogs and delivery among the provinces, establishing whether additional delivery is increasing or decreasing in provinces and the corresponding impact on backlogs. In order to do so it is necessary to analyse delivery at provincial levels.

\section{Provincial level}

The provincial differences and the role of initial conditions of access on the delivery of water services among the provinces, was investigated, to establish whether the higher levels of delivery are in the provinces that had the highest existing level of access in 1994, in other words, whether the lower levels of delivery are in the provinces that had the lowest existing level of access (low initial conditions). In Tables $3 a$ to $3 b$ we present numerical records of total household numbers, households with access to piped water, backlog and percentage of households with access to piped water at provincial level, for the period 1995 to 2005.

\begin{tabular}{|l|c|c|c|c|}
\hline \multicolumn{5}{|c|}{ Table 3a } \\
Water access at provincial level \\
\hline Province & HH 1995 & $\mathbf{1 9 9 5}$ Piped & $\begin{array}{c}\mathbf{1 9 9 5} \\
\text { Backlog }\end{array}$ & $\begin{array}{c}\% \\
\text { Piped }\end{array}$ \\
\hline Western Cape & 960450 & 915842 & 44608 & 95 \\
\hline Eastern Cape & 1244999 & 701598 & 543401 & 56 \\
\hline Northern Cape & 188782 & 178050 & 10732 & 94 \\
\hline Free State & 662654 & 571331 & 91323 & 86 \\
\hline KwaZulu-Natal & 1575726 & 1031198 & 544528 & 65 \\
\hline North West & 730646 & 594651 & 135995 & 81 \\
\hline Gauteng & 2079563 & 2014663 & 64900 & 97 \\
\hline Mpumalanga & 535123 & 407884 & 127239 & 76 \\
\hline Limpopo & 825945 & 596018 & 229927 & 72 \\
\hline
\end{tabular}

Source: Computed from Stats SA Household Surveys 95

Backlogs can be seen from a number of perspectives. From one perspective the increased numbers represent the increase in the number of households; from another perspective this could be the decline in operational water schemes in rural areas.

\begin{tabular}{|l|c|c|c|c|}
\hline \multicolumn{5}{|c|}{ Table 3b } \\
Water access at provincial level \\
\hline Province & HH 2005 & 2005 Piped & $\begin{array}{c}\mathbf{2 0 0 5} \\
\text { Backlog }\end{array}$ & $\begin{array}{c}\% \\
\text { Piped }\end{array}$ \\
\hline Western Cape & 1283775 & 1261052 & 22723 & 98 \\
\hline Eastern Cape & 1731898 & 1132238 & 599660 & 65 \\
\hline Northern Cape & 243429 & 232013 & 11416 & 95 \\
\hline Free State & 857775 & 817068 & 40707 & 95 \\
\hline KwaZulu-Natal & 2456962 & 1950712 & 506250 & 79 \\
\hline North West & 1032969 & 879847 & 153122 & 85 \\
\hline Gauteng & 2983460 & 2891100 & 92360 & 97 \\
\hline Mpumalanga & 792524 & 664975 & 127549 & 84 \\
\hline Limpopo & 1344574 & 973077 & 371497 & 72 \\
\hline
\end{tabular}

Source: Computed from Stats SA Household Surveys 2005

Tables $3 \mathrm{a}$ and $3 \mathrm{~b}$ above show that over the period 1995 to 2005 the Eastern Cape was found to have the largest backlog, followed by KwaZulu-Natal and then Limpopo. What is clear is that several provinces, such as Limpopo, the Eastern Cape and Gauteng, have an increased backlog while the Free State, KwaZulu-Natal, and the Western Cape show a decline. In Table 4 the actual numerical changes over Phases I and II are presented.

In Phase I we observe from Table 4 (ranked by volume of change in backlog in descending order, where $\mathrm{Ch}$ I and $\mathrm{Ch}$ II represent changes in backlog in Phases I and II, respectively) that the backlog decreased in the Western Cape by $72 \%$, in the Free State by $64 \%$, in North West by $14 \%$, in Gauteng by $60 \%$ and in Mpumalanga by $34 \%$. Backlog increased in the other provinces, with the highest increase, of over $100000(20 \%)$ being in the Eastern Cape. We observe a different scenario in Phase II from Table 4. The provinces (Gauteng, Western Cape, Free State, Mpumalanga and North West) that manifested a decreasing trend in backlog in Phase I show increase in backlog in Phase II, while provinces like the Eastern Cape that reflected huge increases in backlog in Phase I show a decreasing backlog in Phase II.

We proceed in Table 5 by showing total delivery among the provinces in the 2 phases as a major indication of the efforts of the provinces towards eliminating the backlogs. 


\begin{tabular}{|l|c|c|c|c|c|c|}
\hline \multicolumn{7}{|c|}{ Table 4 } \\
\hline Province & Ch I & \% Ch I & Rank I & Ch II & \% Ch II & Rank II \\
\hline Western Cape & -31966 & -71.7 & 4 & 10081 & 79.7 & 5 \\
\hline Eastern Cape & 109756 & 20.2 & 9 & -53497 & -8.2 & 2 \\
\hline Northern Cape & 5099 & 47.5 & 6 & -4415 & -27.9 & 3 \\
\hline Free State & -58039 & -63.6 & 1 & 7423 & 22.3 & 4 \\
\hline KwaZulu-Natal & 35151 & 6.5 & 7 & -73429 & -12.7 & 1 \\
\hline North West & -18827 & -13.8 & 5 & 35954 & 30.7 & 6 \\
\hline Gauteng & -39129 & -60.3 & 3 & 66589 & 258.4 & 8 \\
\hline Mpumalanga & -43734 & -34.4 & 2 & 44044 & 52.7 & 7 \\
\hline Limpopo & 41655 & 18.1 & 8 & 99915 & 36.8 & 9 \\
\hline
\end{tabular}

Source: Computed from Stats SA Household Surveys 95-05

\begin{tabular}{|l|c|c|c|c|}
\hline \multicolumn{5}{|c|}{ Table 5 } \\
The Provincial level additional delivery Phases I \& II \\
\hline Province & $\begin{array}{c}\text { Ph I Total } \\
\text { Delivery }\end{array}$ & $\begin{array}{c}\text { Ph I } \\
\text { Rank }\end{array}$ & $\begin{array}{c}\text { Ph II Total } \\
\text { Delivery }\end{array}$ & $\begin{array}{c}\text { Ph II } \\
\text { Rank }\end{array}$ \\
\hline Western Cape & 195152 & 5 & 150058 & 4 \\
\hline Eastern Cape & 42893 & 9 & 312859 & 3 \\
\hline Northern Cape & 43494 & 8 & 10469 & 9 \\
\hline Free State & 159973 & 7 & 85764 & 7 \\
\hline KwaZulu-Natal & 393254 & 1 & 526260 & 2 \\
\hline North West & 177615 & 6 & 107581 & 6 \\
\hline Gauteng & 304636 & 2 & 571801 & 1 \\
\hline Mpumalanga & 244713 & 4 & 23511 & 8 \\
\hline Limpopo & 259519 & 3 & 117540 & 5 \\
\hline
\end{tabular}

Source: Computed from Stats SA Household Surveys 95 - 05

Table 5 analyses how the provinces have performed in terms of delivery. Total additional delivery is presented in Table 5 (ranked by volume of delivery, where Del I and Del II represent total delivery in Phases I and II, respectively). Dramatic changes in total delivery between Phase I and II could be noted in the Eastern Cape, where delivery increased from 43000 in Phase I to 313000 in Phase II, delivery in Free State decreased from 160000 in Phase I to 86000 in Phase II while Mpumalanga was shown to have made a dramatic decrease in delivery from 245000 in Phase I to 24000 in Phase II.

Figure 2 graphically highlights the outcome of strides in delivery compared with changes in households in the provinces, to further draw attention to some conception of effectiveness in the provinces, as in the previous tables. On this basis, KwaZulu-Natal, Western Cape, Free State, Northern Cape and Mpumalanga appear to at least be measuring up with the pressure of additional demand as a result of household growth However, this does not take into account the demands due to prior backlogs.

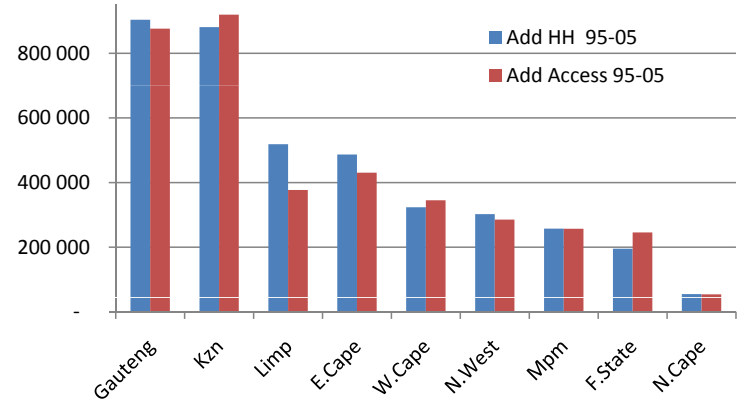

Figure 2

Comparing change in household numbers and access
Another approach towards the comparative analysis of performance of provinces would be to make an assumption that holds the total numbers constant at 2005 , assuming no additional demand, and then computing the time it would take the provinces to eliminate backlog at the rates of delivery in Phases I and II.

\begin{tabular}{|c|c|c|c|}
\hline \multicolumn{4}{|c|}{$\begin{array}{c}\text { Table } 6 \\
\text { The number of years to end backlog }\end{array}$} \\
\hline Province & $\begin{array}{c}\text { Average } \\
\text { annual deliver }\end{array}$ & $\begin{array}{c}2005 \\
\text { Backlog }\end{array}$ & $\begin{array}{l}\text { Years to end } \\
\text { backlog }\end{array}$ \\
\hline Western Cape & 30012 & 22723 & 01 \\
\hline Eastern Cape & 62572 & 599660 & 10 \\
\hline Northern Cape & 2094 & 11416 & 05 \\
\hline Free State & 17153 & 40707 & 02 \\
\hline KwaZulu-Natal & 82285 & 506250 & 06 \\
\hline North West & 21516 & 153122 & 07 \\
\hline Gauteng & 114360 & 92360 & 01 \\
\hline Mpumalanga & 2476 & 127549 & 52 \\
\hline Limpopo & 23508 & 371497 & 16 \\
\hline South Africa & 355975 & 1925284 & 05 \\
\hline
\end{tabular}

Source: Computed from Stats SA Household Surveys 95 - 05

Even on this unrealistic basis, as shown in Table 6, it will take Mpumalanga (which is not close to meeting the annual increase in households) up to 52 years to meet the demand posed by the historic backlog, Limpopo (which is also in a similar position) will take 16 years, and the Eastern Cape (which has annual access greater than the annual increase in households) 10 years. By way of comparison, the Western Cape and Gauteng could end the backlog in a single year.

There is a considerable range of differences in the changes in backlog at the provincial level. Although in the tables above it has been shown that there has been a substantial increase in delivery, which in most provinces has approached meeting the increasing number of households in each province, this increased delivery has unexpectedly not made major inroads into the prior backlog.

\section{Provincial grouping}

A suitable comparative analysis of water service delivery in the provinces would require fairly consistent data sets for each of the provinces. In an effort to control for the inconsistency we employ a grouping system of provinces with similar characteristics. Though this does not entirely eliminate the inconsistency, it could give a better depiction of events between the phases over time. We made use of 3 groups of the 9 South 
African provinces; the grouping was made with respect to their initial conditions and rate of basic water service delivery over time. This was done to control for inconsistent data, as explained above, and also to reduce the problem of mismatching comparisons of provinces that initially had very different circumstances in terms of level of access, socioeconomic and political scenarios.

\section{The groups and basis for the grouping}

\begin{tabular}{|l|l|l|}
\hline \multicolumn{3}{|c|}{ Table 7 } \\
\multicolumn{2}{|c|}{ The provincial groups } \\
\hline Group A & Group B & Group C \\
\hline Western Cape & Northern Cape & Eastern Cape \\
\hline Gauteng & North West & Mpumalanga \\
\hline Free State & KwaZulu-Natal & Limpopo \\
\hline
\end{tabular}

Table 7 shows the provincial groups A, B and C with Group A consisting of Gauteng, Western Cape and the Free State. These provinces have similar initial conditions and are economically/ technically more empowered to deliver; provinces in this group had recorded basic access above $95 \%$ at the start of the research period (1994/5). The intermediate group, Group B, consists of the Northern Cape, North West and KwaZulu-Natal. KwaZuluNatal had lower initial percentage access than the two other provinces in this group, but it was included in this group based on progressive trend in delivery. Group $\mathrm{C}$ comprises of the Eastern Cape, Mpumalanga and Limpopo, which ranked lowest in terms of access. The prominent feature of the grouping is the reflection of the historical subdivision of the country during the apartheid era according to 'homelands', as shown in Fig. 3. Group C, which ranks lowest in terms of adequate water access, provides a good representation of the former homeland states.

Apart from looking at backlogs, initial basic access levels and the trend over time, another important basis for the grouping was to look at provincial advances at the 'rudimentary level'. Here rudimentary access as the next level of delivery is created to account for households which, although they did not fall into the basic service delivery category, have access to some sort of water delivery which may not meet the basic service standards. This category helps to clarify who is served and at what level of service delivery, and also enables community

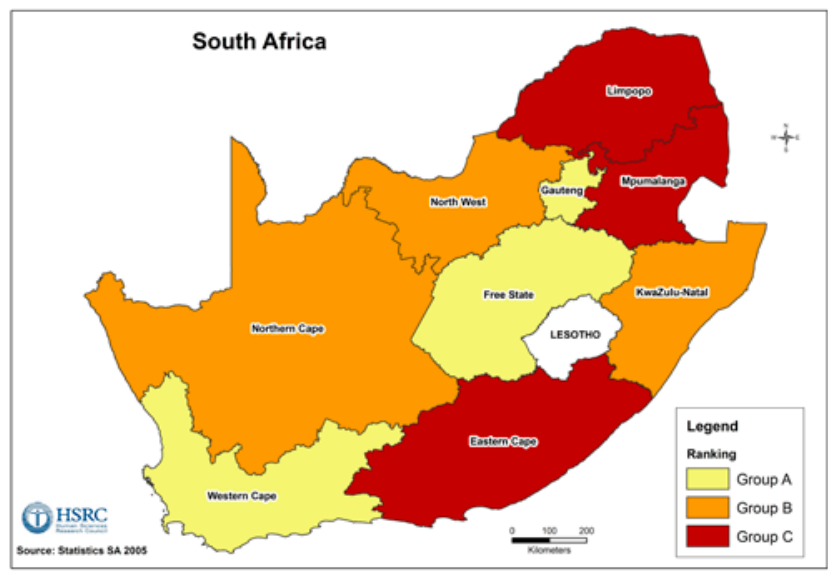

Figure 3

Location of the provincial groups

Source: Prepared by Zama S of GIS Unit of the Human Sciences Research Council and individual self-help efforts towards service delivery to be represented in the delivery analysis. Under the rudimentary access category are households whose main water source are a public tap more than $200 \mathrm{~m}$ away from the dwelling, neighbour's tap, borehole (on-site or off-site), water-carrier/tanker, dam/pool or well. Studies (Hemson and Nnadozie, 2006) have shown that the majority of households seemed to transit from the 'no access' category to 'rudimentary access' before getting into the 'basic access' category, especially for the more rural provinces. For instance, another reason why KwaZulu-Natal featured in Group B is the trend reflecting that a good proportion of the households in the province witnessed a direct improvement from 'no access' in Phase I to 'basic access' in Phase II without having to pass through the rudimentary stage, implying better quality service delivery in KwaZulu-Natal than Eastern Cape, Limpopo and Mpumalanga.

Tables $8 \mathrm{a}$ to $8 \mathrm{c}$ provide a summary of average annual delivery, average annual change in backlog and average annual change in household number for all of the groups of provinces (A, B, C).

\section{Table 8a}

Delivery, backlog and access in Phases I and II, Group A

\begin{tabular}{|l|c|c|}
\hline Parameter & Phase I & Phase II \\
\hline Annual delivery & 164940 & 161525 \\
\hline Annual change in backlog & -32284 & 16819 \\
\hline Annual change in HH & 132657 & 178343 \\
\hline Piped HH & 4161597 & 4969220 \\
\hline Total households (HH) & 4233294 & 5125010 \\
\hline
\end{tabular}

Source: Computed from Stats SA Household Surveys 95 - 05

\section{Table 8b}

Delivery, backlog and access in Phases I and II, Group B

\begin{tabular}{|l|c|c|}
\hline Parameter & Phase I & Phase II \\
\hline Annual delivery & 187299 & 105895 \\
\hline Annual change in backlog & 5356 & -8378 \\
\hline Annual change in HH & 187655 & 97517 \\
\hline Piped HH & 2533096 & 3062572 \\
\hline Total households (HH) & 3245774 & 3733360 \\
\hline
\end{tabular}

Source: Computed from Stats SA Household Surveys 95

\section{Table 8c}

Delivery, backlog and access in Phases I and II, Group C

\begin{tabular}{|l|c|c|}
\hline Parameter & Phase I & Phase II \\
\hline Annual delivery & 155503 & 88555 \\
\hline Annual change in backlog & 26919 & 18092 \\
\hline Annual change in HH & 182423 & 106648 \\
\hline Piped HH & 2327513 & 2770290 \\
\hline Total households (HH) & 3335757 & 3868996 \\
\hline
\end{tabular}

Source: Computed from Stats SA Household Surveys 95

Table 8a shows that during Phase I, 1995-99, the initial base backlog for Group A was almost approaching elimination, implying that average annual delivery met annual additional demand and was enough to gradually reduce the initial base backlog. However, the second phase manifests an annual increase in backlogs. Table 8 a shows an average annual decrease in backlog of about 30000 per annum during the first phase. The second phase (1999-2005) shows an annual increase in backlog of almost 17000 households per annum. Annual additional connections could be seen to be almost steady at about 160000 per annum, while additional demand rose between Phases I and II from about 130000 per annum to 
180000 per annum. This explains the rising backlog during the second phase.

In Table $8 b$ the Group B provinces show a different scenario: in Phase I the initial base backlog was rising at about 5000 per annum while the second phase manifests an annual decrease of 8000 in backlog, although annual additional connections were reduced from 180000 during the first phase to about 100000 in the second phase. The declining backlog could be as a result of declining annual additional demand, which has reduced considerably from almost 190000 during the first phase to about 100000 in the second phase.

As shown in Table 8c, Group C provinces witnessed a rising initial base backlog during Phase I of about 27000 per annum. The second phase also manifests a rising trend in back$\log$ although reduced to 18000 per annum. Additional connections reduced from 155000 per annum during the first phase to about 90000 during the second phase. Although additional annual demand declined from about 180000 to about 100000 between the phases, it did not have the desired effect on the backlog. This could be as a result of the inability of the Group $\mathrm{C}$ provinces to deal with the initial base backlog.

In general, on a comparative basis, the initial condition is most favourable for Group A (Western Cape, Gauteng and Free State) provinces that started with a total backlog of 200000 in 1995. This initial backlog was declining annually at 30000 per annum during the first phase. The Group A provinces have also been consistent with additional delivery at 160000 per annum. These provinces have also witnessed a rising trend in additional demand, which could easily be attributed to in-migration, as the results of the 2006 Community Survey show that Gauteng and the Western Cape are the biggest recipients of internal migrants in South Africa with migration at $43 \%$ and 23\% of the population, respectively (Statistics South Africa, 2007). The Group C (Eastern Cape, Mpumalanga and Limpopo) provinces started with the most unfavourable initial conditions, with a backlog of 900000 in 1995. Although the annual additional backlog decreased from 27000 in 1995 to 18000 in 2005, this cannot be attributed to accelerated delivery, but could be due to out-migration to the Group A provinces, as all of the provinces in this group reflected that more than $20 \%$ of the population had migrated from the provinces, according to the 2007 Community Survey (Statistics South Africa, 2007).

It could be noted from Tables $8 \mathrm{a}$ to $8 \mathrm{c}$ that, although average annual delivery was almost stable for Group A for Phase I and II, annual delivery decreased marginally by $2 \%$. On the other hand, Groups B (Northern Cape, Kwazulu-Natal and North West) and $\mathrm{C}$ both show a substantial decline of about $43 \%$ in average annual delivery from Phase I to Phase II. Backlog was declining annually in Phase I for Group A and an increasing backlog in Phase II is evident for the same group. For Group A the annual change in household numbers increased from Phase I to II by about $34 \%$. On the other hand, Groups B and $\mathrm{C}$ show a decline in annual change in household number between Phases I and II.

For Group A, percentage access rose from 95\% in 1995 to $98 \%$ in 1999 and maintained the percentage access at $98 \%$ till 2005. This pattern of access could be noted where percentage access rose from the initial base of $94 \%$ in 1995 to $98 \%$ in 1999 and remained steady at $98 \%$ till 2005, irrespective of average annual delivery of over 160000 in the Group A provinces. The inhibiting factor for reaching the $100 \%$ access mark could be attributed to in-migration from the Group B and C provinces (Statistics South Africa, 2007). Tables $8 \mathrm{~b}$ and $8 \mathrm{c}$ show that annual additions to household numbers have been on the decrease among the provinces in Groups B and $\mathrm{C}$ but on the increase for Group A. This implies that people could be out-migrating from $\mathrm{B}$ and $\mathrm{C}$ to Group $\mathrm{A}$ and thus the resultant effect is the persistent backlog in the Group A provinces at about $2 \%$. For Group B, an increase in percentage access from $72 \%$ in 1995 to $80 \%$ in 1999 and $83 \%$ in 2005 is noted. Although delivery slowed, percentage access increased as a result of a decreasing number of additional households over the years. This group of provinces could be said to be passing through the rapid rate of growth in percentage access. For Group C provinces, Tables 8c indicates that they started with the lowest access, at about $66 \%$, in 1995 . Although percentage access increased from $66 \%$ in 1995 to $69 \%$ in 1999 and to $71 \%$ in 2005 , delivery declined significantly and additional household numbers also declined.

The proportion of households with basic access for Group A could be described using the logistic model, as in Eq. (1). Available data show that Group A had completed the movement on the logistic line having reached the limiting steady state at $98 \%$ as shown in Fig. 4. Group B could be described as being in the rapid advancement stage following an exponential function (Eq. (2)). The model predicts that, all things being equal, the Group B provinces could achieve $100 \%$ access in about 2015 at the current rate of delivery and demographic change. A boost in delivery could make a huge difference in enabling these provinces to approach $100 \%$ access, as these provinces are favoured by out-migration. We observed the Group $\mathrm{C}$ provinces to be at the slow stage of growth following a linear model (Eq. (3)). Though these provinces are also favoured by out-migration, lack of sustained delivery and improved capacity are major issues of concern and delivery dropped quite remarkably.

The models that describe the patterns of access among the provincial groups are given in Eqs. (1) to (3) below:

$$
\begin{aligned}
& A(t)=\frac{K}{1+\left(\frac{K}{A_{0}}-1\right) \exp \left(-r_{0} t\right)} \\
& B(t)=B_{0} \exp ^{r t} \\
& C(t)=C_{0}+r t
\end{aligned}
$$

These patterns of growth are represented graphically for the respective provincial groups in Fig. 4.

A notable inference from the numerical outcomes and graphics presented so far is the important issue of development of delivery capacity in the various provinces. The Group A provinces could be noted to have made remarkable progress in terms of sustaining levels of delivery and even improving on delivery figures, from 660000 delivered in Phase I to 800000

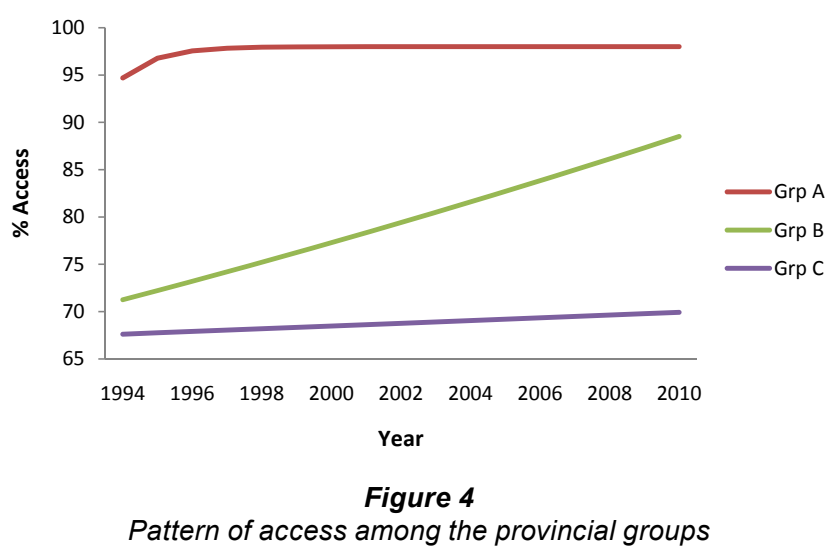


delivered in Phase II. However, Groups B and C show decline in delivery over the phases, where Group B was down from 700000 to 500000 , and Group C from 600000 to 400000 from Phase I to Phase II. This highlights issues and questions around capacity and capacity building in these provinces, i.e., the ability of the provinces to at least sustain a steady delivery thrust and gradually improve on it.

Variations on level of access and delivery over time could be noted when all of the provinces are considered separately. When the provinces are grouped according to some matching criteria, the wide variations are spread across the provinces and less fluctuation could be noted. Delivery slowed in Groups B and C from Phase I to Phase II (95-99 to 00-05), whereas the Group A provinces maintained the delivery thrust between the phases and also had a marginal increase in delivery. While demographic factors such as household fragmentation and internal migration could have played a contributing explanatory role in the access dynamics seen among the provincial groups, the water services national information system (DWA, 2011) outlined factors that may have direct impacts on water backlogs in the provinces. These factors include water infrastructure problems, operational /maintenance issues, water resource problems and housing problems. Infrastructural problems are seemingly spread across the provinces; KwaZulu-Natal is the province with the highest number of cases of no water infrastructure (40\%), followed by Limpopo at $20 \%$. Eastern Cape and Mpumalanga contribute $13 \%$ and $12 \%$ of cases of no water infrastructure, respectively (DWA, 2011). Operation/maintenance problems seem to be a setback peculiar to the Group C provinces; Limpopo accounts for $70 \%$ of cases of operational maintenance issues while Mpumalanga accounts for $29 \%$ (DWA, 2011). South Africa is a semi-arid country; available fresh water reserves should be treasured and managed country-wide as a collective effort. However, the water services national information system reports show that Limpopo accounts for 39\% of backlog issues related to water resource problems, with KwaZuluNatal contributing 30\% and the North West and Mpumalanga contributing $20 \%$ and $10 \%$, respectively (DWA, 2011).

Backlogs due to housing problems featured most prominently for the Group A provinces; Gauteng contributes $45 \%$ in this category and the Western Cape 36\% (DWA, 2011). This could be as a result of high in-migration into these provinces, especially with regard to unskilled and poor migrants as they increase the population and household numbers in the informal settlements.

\section{Conclusion}

This research attempted to evaluate the process of attaining universal access to adequate water in the post-1994 era. An outstanding characteristic of the evaluation process was the very diverse initial conditions of access to basic water services at the dawn of the new South Africa in 1994/95. It was observed from the possible interplay of water infrastructural problems, water resources, demographic factors and delivery capacity (that is, the ability to sustain the delivery thrust) that the declining trend of water service delivery in later years is only applicable to the provinces in Groups B (Northern Cape, KwaZulu-Natal and North West) and C (Eastern Cape, Mpumalanga and Limpopo). The Group A (Western Cape, Gauteng and Free State) provinces show evidence of sustainability of delivery levels and achieved an improvement on additional delivery from 660000 in Phase I to 808000 in Phase II.
The investigation of the dynamics of change in numbers of households and the interaction with demand and access rates of the provincial groups shows that, where the existing service base is low, with a relatively high level of out-migration leading to a decrease in household numbers, the annual rate of delivery is lower than in other provinces and the percentage access rises marginally. In the provinces where the existing service base was higher and there is a relatively lower level of emigration, there is a marginal change in household numbers, the annual rate of delivery is faster and the percentage access rises significantly. In the provinces with the most favourable initial conditions, i.e., those in which the existing service base was the highest, there is remarkable change in household numbers as a result of immigration and the annual rate of delivery is quite sustainable. Percentage access rises at an early stage and remains stable at the limiting value.

In fitting the advancement in access for the provinces to various equations it was observed that the provinces in Group A have progressed along the logistic line, having reached the limiting steady state. Group B could be described as being in the rapid advancement stage. The model predicts that, all things being equal, the Group B provinces could achieve $100 \%$ access in about 2015 if the current rate of delivery and demographic change are maintained. A boost in delivery could make huge differences in enabling delivery levels to approach $100 \%$ access, as these provinces are favoured by out-migration. Group C provinces were found to be at the slow stage of growth, though these provinces are also favoured by out-migration. Lack of capacity is a major issue of concern and delivery dropped quite remarkably. The Group A provinces would require only a small boost in delivery and utilisation at maximum capacity in order to overcome their current limiting tendency to achieve $100 \%$ access, in a year or two, through strategic planning and good understanding of the impact of demographic factors.

The results imply that in as much as service delivery programmes and policies should focus on the formerly disadvantaged poor and rural communities, adequate provision should also be made for the surge of internal and international migrants into urban areas. The slowed rate of delivery in the Group C (Eastern Cape, Mpumalanga and Limpopo) provinces and the in-migration into Group A (Western Cape, Gauteng and Free State) provinces might hinder the attainment of the water target of the millennium development goals in South Africa if the current trend continues.

Future research would entail the extension of this analysis using the 2010 rounds of national household data, as they become available, in order to observe the most recent trends and the changes that may have occurred over the period 2005 to 2010 (Phase III).

\section{References}

BHORAT H, POSWELL L and NAIDOO P (2004) Dimensions of poverty in post-apartheid South Africa 1996 - 2001. Development Policy Research Unit (DPRU), University of Cape Town, Cape Town.

BHORAT H and KANBUR R (2005) Poverty and well-being in postapartheid South Africa: An overview of data, outcomes and policy. Development Policy Research Unit (DPRU), University of Cape Town, Cape Town.

BHORAT H, VAN DER WESTHUIZEN C and GOGA S (2008a) Welfare shifts in the post-apartheid South Africa: A comprehensive measurement of changes. Development Policy Research Unit (DPRU) University of Cape Town, Cape Town. 
BHORAT H, VAN DER WESTHUIZEN C and NAIDOO P (2008b) Shifts in non-income welfare in South Africa: 1993 - 2004 Development Policy Research Unit (DPRU) University of Cape Town, Cape Town.

BONGAART J (2001) Household size and composition in the developing world in the 1990s. Pop. Stud. 55 263-279.

BUDLENDER D (1999) Patterns of poverty in South Africa. Dev Southern Afr. 16 176-246.

CROSS C (2001) Why does South Africa need a spatial policy? Population migration infrastructure and development. J. Contemporary Stud. 19(1) 111-128.

DEVELOPMENT POLICY RESEARCH UNIT (2005) Internal migration to the Gauteng province. DPRU policy brief series, University of Cape Town, Cape Town.

DWA (Department of Water Affairs, South Africa) (2011) Water services access and backlog trends from the water services national information system. URL: http://www.dwaf.gov.za/dir ws/wsnis/ (Accessed 19 February 2011).

DWAF (DEPARTMENT OF WATER AFFAIRS AND FORESTRY, SOUTH AFRICA) (2004) A history of first decade of water service delivery in South Africa 1994 to 2004. Department of Water Affairs and Forestry, Pretoria.

HEMSON D and GALVIN M (2006) Water service rights in laws, conventions, and policies in South Africa. Human Sciences Research Council, Pretoria.

HEMSON D and O'DONOVAN M (2006) Putting the numbers to the scorecard: presidential targets and the state of delivery. In Buh-lungu S, Daniel J, Southall R and Lutchman J (eds.) State of the Nation: South Africa, 2005-2006. Human Sciences Research Council, Pretoria.

HEMSON D and NNADOZIE R (2005) Transforming rural areas? Service delivery and rural development. Proc. HSRC. Winter. Conf., 27-28 July 2005, Johannesburg.

HIRSCHOWITZ R and ORKIN M (1997) Inequality in South Africa: Findings from the 1994 October Household Survey. Soc. Indicator Res. 41 119-136.

KOK P, O'DONOVAN M, BOUARE O and VAN ZYL J (2003) Postapartheid patterns of internal migration in South Africa. Human Sciences Research Council, Pretoria.

KRUGELL W, OTTO H and VAN DER MERWE J (2009) Local municipalities and progress with the delivery of basic services in South Africa. School of Economics, North West University, Potchefstroom.
LE ROUX BOOYSEN F (2003) The extent of, and possible explanations for provincial disparities in progress on reconstruction and development in South Africa. Dev. Southern Afr. 20 21-48.

MBEKI T (2004) Address to the First Joint Sitting of the Third Democratic Parliament of South Africa, 21 May 2004. Parliament of the Republic of South Africa, Cape Town.

NGWANE AK, YADAVALLI VSS and STEFFENS FE (2003) Poverty: Deprivation in terms of basic needs. Dev. Southern Afr. 19 545-560.

SOUTH AFRICAN DATA ARCHIVE (1995) October Household Survey 1994. Statistics South Africa, Pretoria.

SOUTH AFRICAN DATA ARCHIVE (1996) October Household Survey 1995. Statistics South Africa, Pretoria.

SOUTH AFRICAN DATA ARCHIVE (1997) Population Census 1996. Statistics South Africa, Pretoria.

SOUTH AFRICAN DATA ARCHIVE (1998) October Household Survey 1997. Statistics South Africa, Pretoria.

SOUTH AFRICAN DATA ARCHIVE (1999) October Household Survey 1998. Statistics South Africa, Pretoria.

SOUTH AFRICAN DATA ARCHIVE (2000) October Household Survey 1999. Statistics South Africa, Pretoria.

SOUTH AFRICAN DATA ARCHIVE (2002) Population Census 2001. Statistics South Africa, Pretoria.

SOUTH AFRICAN DATA ARCHIVE (2003) General Household Survey 2002. Statistics South Africa, Pretoria.

SOUTH AFRICAN DATA ARCHIVE (2004) General Household Survey 2003. Statistics South Africa, Pretoria.

SOUTH AFRICAN DATA ARCHIVE (2005) General Household Survey 2004. Statistics South Africa, Pretoria.

SOUTH AFRICAN DATA ARCHIVE (2006) General Household Survey 2005. Statistics South Africa, Pretoria.

STATISTICS SOUTH AFRICA (1996) The people of South Africa population census 1996: Census brief. Statistics South Africa, Pretoria.

STATISTICS SOUTH AFRICA (2001) Census 2001: Census brief. Statistics South Africa, Pretoria.

STATISTICS SOUTH AFRICA (2007) Statistical release, 2006 community survey. Statistics South Africa, Pretoria.

UNITED NATIONS (2000) UN millennium development goals. URL: http:www.un.org/millenniumgoals/ (Accessed 03 March 2010).

ZAMA S (2011) GIS map showing South African provinces according water access grouping. GIS Unit, HSRC, Pretoria. 
Available on website http://www.wrc.org.za ISSN 0378-4738 (Print) = Water SA Vol. 37 No. 3 July 2011 